\title{
A PROPÓSITO DE JUDÍOS, MOROS Y CRISTIANOS: EL GÉNERO 'RELATO DE VIAJES' EN CAMILO JOSÉ CELA
}

\author{
LUIS ALBURQUERQUE GARCÍA
}

Instituto de la Lengua Española (CSIC)

\section{Los 'Relatos de viajes' en la obra de Camilo José Cela}

Sabemos que los 'relatos de viajes' de Camilo José Cela suponen una parte fundamental de su producción literaria. Desde 1944, año de la publicación del Viaje a la Alcarria, hasta 1965, fecha de la aparición del Viaje al Pirineo de Lérida, se suceden otras composiciones dentro de este género mayor en la obra de C.J.C.: Cuaderno de Guadarrama (1952), Del Miño al Bidasoa (1952), Judios, moros y cristianos (1956) y Primer viaje andaluz (1959) ${ }^{1}$. Los trazos esenciales de su escritura se apuntan ya en esta serie que marcará su trayectoria literaria.

Además, en Cela es difícil establecer una frontera tajante entre estos relatos y su aportación novelística, pues las pautas que caracterizan a aquéllos se deslizan permanentemente en ésta, y viceversa. Precisamente porque el relato de viajes no pierde nunca su aspiración literaria e, incluso, a veces, apunta hacia lo ficticio, sin necesidad de despegarse de su alcance histórico o documental, comparte características con el género de la novela, cuyo intento de verosimilitud puede investirla a veces de un vago rango histórico o pseudo-documental.

En C.J.C. esto se advierte con claridad. Sus 'relatos de viajes' son eminentemente literarios a la vez que se asientan en una fuerte base documental y de experiencia viajera. Y a la vez, sus novelas (recordemos San Camilo, 1936 o La colmena), aunque de ficción, están amparadas por un marco histórico que se percibe con nitidez como algo procedente de la experiencia vital del novelista.

\footnotetext{
${ }^{1}$ Paul Ilie incluye Nuevas andanzas y desventuras de Lazarillo de Tormes dentro del género. Cfr. su libro La novelística de Camilo José Cela, Madrid, Gredos, 1963, p. 112.
}

Rlit, LXVI, 132 (2004), 503-524 
Se puede decir que función poética y función representativa muestran la cara y la cruz de la moneda de este género. Cuanto más nos acercamos hacia la primera, más palpable se hace su condición literaria, y a la inversa, cuanto más nos aproximamos a la segunda, más se acentúa su carácter histórico y documental. En el filo de ambas funciones se desenvuelve este género que algunos han denominado, por esta razón, bifronte y cuya naturaleza ambigua lo ha llevado en ocasiones a ser desterrado del palenque literario ${ }^{2}$.

Detenerse a analizar esta parte de la obra de Cela nos facilita, pues, adentrarnos en el mundo temático y estilístico de su fecunda narrativa. Escojo el libro Judíos, moros y cristianos. Notas de un vagabundaje por Ávila, Segovia y sus tierras (publicado en 1956 en la editorial Destino de Barcelona), por ser poco atendido dentro de los de esta serie, debido quizá a la sombra proyectada por el Viaje a la Alcarria, primera entrega de este rosario de relatos viajeros, cuyo éxito eclipsó en cierto modo la aparición de los restantes volúmenes que completan este género dentro de su obra ${ }^{3}$.

\section{El 'RELATO DE VIAJES' Y SUS CARACTERÍSTICAS ESENCIALES}

Cuando hablo de los 'relatos de viajes' me estoy refiriendo a un género narrativo muy específico. La denominación habitual de 'libros de viajes' como rótulo caracterizador resulta, la mayoría de las veces, algo difuso e inconcreto, por excesivamente abarcador. Las grandes obras de la literatura universal podrían considerarse dentro de este género sin excesiva violencia.

Por eso, tal vez sea más conveniente hablar de 'relatos de viajes' para referirnos a este género específico cuyos rasgos distintivos lo caracterizan como tal, aunque a veces sus contornos interfieran con otras modalidades limítrofes, lo que ya ha sido objeto de mi atención en ocasiones anteriores ${ }^{4}$.

\footnotetext{
${ }^{2} \mathrm{Al}$ carácter bifronte de estos textos se ha referido Sofía CARRIzo Rueda en su estudio Poética del relato de viajes, Kassel, Reichenberger (Problemata Literaria, 37), 1997. Algunas consideraciones acerca de estos discursos ambiguos pueden verse en Miguel Ángel GARRIDO GALLARDO, «Pragmática literaria: las columnas de Francisco Umbral», en La Musa de la retórica. Problemas y métodos de la ciencia de la literatura, Madrid, CSIC, 1994, pp. 214-229.

${ }^{3}$ Un estudio de conjunto sobre las novelas de C.J.C., que incluye los 'relatos de viaje' y un capítulo dedicado a Judíos, moros y cristianos, puede verse en Robert KIRSNER, The novels and travels of Camilo José Cela, Chapel Hill, North Carolina Press (Studies in the Romance Languages and Literatures, number 43), 1966.

${ }^{4}$ «Los «libros de viaje» como género literario», en Estudios sobre literatura de viajes, Madrid, CSIC (en curso de publicación); y también «Consideraciones acerca del género 'relato de viajes' en la literatura del Siglo de Oro», en Carlos MATA y Miguel Zugasti (eds.), Actas del Congreso el Siglo de Oro en el nuevo milenio (septiembre 2003), Pamplona, Eunsa (en prensa).
} 
Sus rasgos principales quedarían resumidos así: discurso articulado con motivo de un viaje; marcas correspondientes de itinerario, cronología y lugares; narración subordinada a una intención descriptiva; utilización de la primera persona (a veces, la tercera), que remite siempre a la intención del autor; y aparición de ciertas figuras literarias que, no siendo exclusivas del género, sí resultan determinantes en compañía de los demás.

Los 'relatos de viaje' de C.J.C. responden a las pautas ahora enunciadas con notoria fidelidad. El motivo del viaje, el itinerario, la cronología, los lugares, las descripciones, el retrato de ambiente, la tercera persona (el vagabundo, que no es otro que el narrador, se erige en foco a través del que se percibe el discurso, que remite siempre a la persona del autor) y la intención inequívocamente poética o literaria, conforman el esqueleto de estos textos que entroncan con toda la tradición anterior del género en nuestra literatura.

No voy a establecer su genealogía completa ahora, pero sí parece claro que los 'relatos de viaje' de C.J.C. suponen una cierta continuidad con la literatura viajera noventayochista, aunque con algunas diferencias, como luego veremos.

Nos encontramos ante un género con una tradición literaria muy consolidada, que alcanza una madurez bastante notable en la pluma de C.J.C. y que, en el conjunto de su obra en particular y en el de la literatura de su época en general, supone una aportación de primer orden. Pienso que el estudio de estas obras en su totalidad o individualmente (como hacemos ahora al estudiar en concreto la obra Judíos, moros y cristianos), nos lleva a la raíz misma de muchos de los procedimientos de la narrativa de Cela que se advertirán también en el resto de su obra literaria no «viajera».

Tres son, me parece, los pilares fundamentales de este género literario sobre los que se asientan los rasgos arriba apuntados: el primero, expresado en forma negativa, se puede enunciar como la inexistencia de una verdadera trama en el relato. Se descubre un hilo narrativo muy endeble (el viaje del protagonista) que actúa como cañamazo, en lugar de una trama sólida; lo cual llama poderosamente la atención y sirve como marca inequívoca frente a otros géneros como, por ejemplo, la novela, en cualquiera de sus manifestaciones. El motivo del viaje actuaría, por tanto, como único motor de enlace entre los capítulos.

El recorrido que hace el vagabundo en Judios, moros y cristianos por tierras de Ávila y Segovia no tiene otra justificación más que el mismo viaje; no es motivado por ninguna otra razón. No hay, pues, un argumento sólido que se pueda rastrear a lo largo de los distintos capítulos que conforman el libro. El desenlace lógico y normal con que se suelen cerrar o terminar los relatos está aquí ausente. Las posibles tramas se desenvuelven dentro de cada episodio de manera exenta: nacen, se desarrollan y mueren aisladamente, sin conexión con el resto, salvo excepciones, en que alguna 
historia suelta se continúa o se cierra en otro capítulo posterior; pero, incluso en estas ocasiones, el desenlace podría haberse evitado sin que peligrara la coherencia del relato.

Los títulos de los ocho capítulos que componen el libro ilustran en cierto modo lo que vengo diciendo: I. Del puerto de Navacerrada al Duero. II. Veinte leguas de Duero. III. De Peñafiel a las puertas de Segovia. IV. Segovia y más castillos. V. Tierra de cantos y de santos. VI. Del sacro Tormes, dulce y claro río. VII. Gredos, espalda de Castilla y VIII. Donde, mejor o peor, se fundó España.

Los capítulos pueden leerse de manera independiente, aunque su orden es preciso, pues viene marcado por razones de verosimilitud geográfica. El propio autor se refiere en el prólogo a este aspecto:

\begin{abstract}
Pensando en todo esto, en todo aquello y también en que a nadie se le ocurrirá jamás viajarse Castilla la Vieja de cabo a rabo y de una sentada, cosa que no sería sensato pensar que es pan comido, el vagabundo ha procurado ordenar su libro con un placentero desorden que permita leerlo a trozos y abrirlo por cualquier lado 5 .
\end{abstract}

El vagabundo recorre, pues, un espacio real, no imaginario, lo que le lleva a precisar el itinerario seguido en todo momento.

El segundo pilar del género, correlato del primero, es la primacía del orden espacial. El espacio crea la verdadera estructura narrativa con sus referencias y descripciones de los lugares que el vagabundo recorre y visita. De ahí que la narración se halle subordinada a la intención descriptiva, que predomina sobre la modalidad narrativa, más propia, por ejemplo, de la novela ${ }^{6}$. Este empeño por la descripción, en muchos casos atenta al detalle en apariencia intrascendente, asoma ya al comienzo del primer capítulo:

[...] y el mirar presto a sorprenderse ante el vencejo que cruza, la perdiz que canta, el dorado escarabajo que trajina, el ciempiés que bulle, el águila que se cuelga al cuello ${ }^{7}$.

\footnotetext{
${ }^{5}$ Judios, moros y cristianos. Notas de un vagabundaje por Ávila, Segovia y sus tierras, Barcelona, Destino, 1956, p. 15. Citaré por esta edición (la primera) cuyo título, de ahora en adelante, abrevio con las siglas $J M y C$.

${ }^{6}$ Opto por hablar de modalidad y no de aspecto, a pesar de las observaciones de Genette, quien prefiere distinguir, dentro del relato, entre aspecto narrativo y descriptivo. Pienso que en el caso concreto de los 'relatos de viajes' nos encontramos más bien con una modalidad específicamente descriptiva, pues es la que soporta el peso cualitativo y cuantitativo del relato, lo que no anula, lógicamente, la presencia de un eje narrativo que, es evidente, nunca puede faltar. Subordinación, pues, todo lo excepcional que se quiera, pero subordinación al fin y al cabo, de lo narrativo a lo descriptivo en este género específico. (Véase Gérard GENETTE, «Fronteras del relato», en AA.VV., Análisis estructural del relato, Buenos Aires, Editorial Tiempo Contemporáneo, 1970, p. 202).

${ }^{7} J M y C$, p. 18.
} 
Por tanto, el 'relato de viajes' tiene una consistencia que viene avalada por su carácter documental y de experiencia vivida en primera persona, aquí disfrazada por la figura del vagabundo que, inequívocamente, remite a la persona del narrador y, a la postre, del autor. En cualquier caso, la verosimilitud de la narración se sustenta en la veracidad de los datos que se nos transmiten y, por supuesto, del pacto que se establece entre lector y autor, mediante el que la información se asume como verídica o, al menos, verosímil. Lo cual no impide que, en ocasiones, la autenticidad de los datos no se contraste adecuadamente, pues la voluntad literaria del autor a veces trasciende la intención documental y discurre por terrenos cuya fidelidad a la historia se subordina al objetivo literario. Puede el lector, ciertamente, encontrarse en el libro -como de hecho ocurre- imprecisiones, datos vagos, afirmaciones poco fundamentadas, inexactitudes al fin $\mathrm{y}$ al cabo; pero serán interpretadas no como falta de seriedad y rigor, sino más bien como licencias propias del género literario, no histórico, con que nos enfrentamos. Volveré sobre este punto más adelante ${ }^{8}$.

La omnipresente intencionalidad literaria que preside este libro queda patente desde el primer momento. Estamos ante la tercera pata del trípode sobre el que se asienta el género. El autor insiste en el prólogo en que las referencias a la realidad interesan sólo como marco del relato. El objetivo último del 'relato de viajes' queda en las páginas liminares del libro perfectamente delimitado: el tenor literario del género huye tanto de los viajes didácticos o educativos, para eso están las guías de viajes (con los datos puros y duros), como de la farragosa erudición más propia de las tesis doctorales o de los libros de historia.

El quid literario se encuentra en un rango distinto que actúa por elevación y evita los dos extremos: ni el dato solo, ni la erudición abrumadora. Así se refiere el autor en el prólogo a esa intención «literaria»:

\begin{abstract}
Los datos se olvidan con facilidad y, además, están apuntados en multitud de libros. Lo que el vagabundo imagina que podrá valer de algo al caminante de Castilla la Vieja que le haga la merced de llevar este libro en la maleta - o al sedentario lector que prefiera la Castilla la Vieja desde su butaca, al lado de la chimenea- es que se le sirva, en vez del dato, el color; en lugar de la cita, el sabor, y a cambio de la ficha, el olor del país: de su cielo, de su tierra, de sus hombres y sus mujeres, de su cocina, de su bodega, de sus costumbres, de su historia, incluso de sus manías. En todo caso, el dato, la cita y la ficha, cuando aparezcan, estarán siempre al servicio del impreciso y tumultuoso "aire" de Castilla".
\end{abstract}

\footnotetext{
${ }^{8}$ Robert Kirsner subraya este hecho, en su libro antes citado, en el capítulo que dedica a Judíos, moros y cristianos: «In his ironical manner, Cela had made it clear in the beginning that he would strive not to appear ostentatious about his erudition because historians too had to eat while he already was making a living as a writer» (The novels and travels of Camilo José Cela, op. cit., p. 168).

${ }^{9} J M y C$, prólogo, p. 14.
} 
LUIS ALBURQUERQUE GARCÍA

\section{El TRATAMIENTO DEL TIEMPO}

Estos tres pilares o cimientos del género sustentan la aparición de otros rasgos específicos que se pueden analizar, me parece a mí, en relación con algunas de las herramientas que la narratología nos ofrece acerca del tiempo y la voz del relato.

Salta a la vista, en primer lugar, que el tiempo de este 'relato de viajes' es un tiempo que coincide exactamente con el tiempo de la historia que se nos cuenta. El narrador da noticia de lo que el vagabundo ve y de lo que le sucede en su periplo por Castilla la Vieja, y lo hace siguiendo un orden cronológico lineal. No hay apenas alteraciones en la sucesión de los acontecimientos que se nos narran. Por decirlo de manera clara, se empieza por el comienzo, se continúa por el medio y se concluye con el final, sin que tal orden se véa afectado por los recursos propios, por ejemplo, de la novela, cuyas analepsis (miradas hacia atrás) y prolepsis (anticipaciones de lo que está por venir) rompen en numerosas ocasiones este paralelismo entre el tiempo de la historia y el tiempo del relato. Se puede decir, pues, que el orden temporal permanece inalterado, ya que la sucesión cronológica lineal (el tiempo de la historia) y su despliegue en el relato (tiempo del relato) se disponen siempre en perfecta sincronía.

El relato de los avatares del vagabundo a lo largo del camino no se «desbarata» con ninguna «anacronía» narrativa. Puntualmente se suceden los amaneceres y los atardeceres y se da cuenta de los acontecimientos de cada singladura con una narración continua y lineal. Supone una especie de grado cero o perfecta coincidencia entre el orden de la historia y el del relato, lo que no implica, ni mucho menos, que sea una aspiración deseable en toda narración, sino más bien, como recuerda Genette, un estado de referencia más hipotético que real ${ }^{10}$. En cualquier caso, no estoy subrayando una virtud del 'relato de viajes', sino constatando un procedimiento normal del género que lo distancia radicalmente del discurso narrativo, ante el que se presenta como una auténtica «anomalía» o estado «atípico».

Fijémonos ahora en la consideración de un segundo aspecto del tiempo: el ritmo del relato. Como sabemos, las cuatro formas tradicionalmente canónicas de la narración, que Genette denomina, equiparándolas a los 'tempos' musicales, «movimientos narrativos» ${ }^{11}$, son la «elipsis», el «sumario», la «escena» y la «pausa», a las que el propio Genette añadirá más adelante la «digresión reflexiva» ${ }^{12}$.

\footnotetext{
${ }^{10}$ Figuras III, Barcelona, Lumen, 1989, p. 92.

"Ibídem, p. 151.

12 Ver Gérard GenetTe, Nuevo discurso del relato, Madrid, Cátedra, 1998, pp. 25-28.
} 
Estas formas narrativas se vinculan entre sí, como sabemos, por su relación con el ritmo del relato, es decir, se distinguen por su mayor o menor velocidad narrativa. Ésta surge de la correspondencia existente entre la duración de la historia y su duración en el relato. Es decir, una duración de la historia (lo que se nos cuenta) se corresponde con una determinada extensión en el discurso narrativo (el espacio que el autor le dedica). Por tanto, la clasificación de las formas narrativas, escalonadas de menor a mayor, según la extensión del discurso narrativo con respecto al tiempo de la historia a que remite, quedaría de la siguiente manera: «elipsis» (velocidad máxima, ya que el tiempo del relato es mínimo con respecto al de la historia que se narra); «sumario» (velocidad rápida, aunque variable, ya que el tiempo del relato es menor que el ocupado por la historia); «escena» (velocidad equilibrada, pues hay un paralelismo entre los tiempos de la historia y del relato que tienden a la simultaneidad); y «pausa» (velocidad lenta, pues el tiempo del relato se demora con respecto al de la historia, con el que no se corresponde) ${ }^{13}$.

En este sentido, se puede constatar que los 'relatos de viaje' son absolutamente ajenos a la «elipsis» y al «sumario» (no se intenta escamotear nada de la historia) y se compadecen más bien con el ritmo narrativo sobre todo de la «escena» y también, como veremos, de la «pausa», ámbitos en los que se produce su desarrollo como género.

La «escena», según lo dicho, se nos presenta como el movimiento narrativo predominante. La equivalencia entre la duración de la historia y la del relato se hace patente mediante el recurso constante a los diálogos y a las descripciones, que normalmente no se despegan del hilo de la acción principal: el «vagabundaje» del protagonista por los pueblos de Castilla la Vieja.

\subsection{El diálogo}

El diálogo despunta como herramienta fundamental que el autor maneja con extraordinaria eficacia. Sin duda contribuye a la simultaneidad propia de estos relatos, que quieren ofrecernos las cosas tal y como fueron vistas por el narrador-viajero en el momento preciso de su ocurrencia. $\mathrm{Su}$ testimonio directo se transmite como si hubiese sucedido en el preciso instante de la narración, aportando esa frescura de lo inmediato de manera muy notable. Desde el primero, apenas comenzado el primer capítulo («-Señora ¿tiene usted algún bocado para un hombre que va de camino? Y la mujer cierra la ventana de golpe. —iMás le valiera trabajar!»),

${ }^{13}$ Un compendio claro y completo de los distintos movimientos aplicados a la narrativa en lengua española se puede ver en Antonio GARRIDO DOMÍNGUEZ, El texto narrativo, Madrid, Síntesis, 1993. 
hasta el último, brevísimo, del capítulo final («-¿Qué tal me sale ya? — ¿Vaya!») los diálogos recorren intermitentemente el trayecto del viajero.

Esa sensación de relato directo la transmite el diálogo, apenas interrumpido, del vagabundo con los personajes que se cruzan en su camino. A veces fluye, incluso, sin la presencia de un interlocutor: es el vagabundo que habla consigo mismo:

[...] el vagabundo, quizás para darse los ánimos que aún no le faltaban pero que ya se le iban gastando, se puso a hablar consigo mismo en alta voz. -Parece que llueve, ¿eh, buen hombre? - Pues yo creo que no, distinguido caballero, que lo que pasa es que llueve. - Pues eso, pues eso es lo que yo le vengo diciendo, buen hombre. - $\mathrm{Y}$ yo, distinguido caballero, y yo. El vagabundo, a veces, se divierte hablando a solas para ensayarse en el complicado arte de no llegar a un acuerdo jamás ${ }^{14}$.

En otra ocasión, el narrador hace explícito el divertimento del diálogo fingido:

[...] Y contarme largas historias, complicadas historias de amor, bellas y doradas historias de amadores adolescentes, rubios y desesperados como el trigo maduro: «¿Me querrás siempre?», «Siempre te querré». «¿No me abandonarás nunca?», «Nunca te abandonaré». A mí, señor, como tengo tanto tiempo, me gusta andar a vueltas con las cosas, mirarlas por el derecho y por el revés, verlas por la mañana, olerlas por la tarde y palparlas por la noche ${ }^{15}$.

\subsection{La «descripción escénica»}

Las descripciones, por otro lado, ocupan una gran parte del relato. Están vinculadas al tenue hilo narrativo del viaje, porque se integran dentro de la acción del vagabundo. No puedo dejar de recordar en este punto la preocupación por el léxico que manifiesta el autor en todo momento. Es muy evidente desde las primeras páginas del libro $\mathrm{y}$, por si pudiera pasar inadvertido este interés, en varias ocasiones se hace elenco de algunas palabras, de uso poco frecuente, con su significado o se recurre al diccionario de la lengua ${ }^{16}$.

${ }^{14} J M y C$, p. 52.

$15 J M y C$, p. 33

${ }^{16} J M y C$, pp. 36-37, 123, 238. Este afán por buscar la palabra apropiada en cada momento, aunque esté en desuso, le convierte a Cela en un verdadero renovador del léxico. En este sentido es un continuador de la tarea llevada a cabo por muchos de los escritores del 98, como por ejemplo, Unamuno o Azorín. Zamora Vicente lo recordaba en su estudio dedicado a Cela: «Nunca se agradecerá bastante a Camilo José Cela este fervoroso esquilmo de la lengua, hecho con toda conciencia, luminosamente. Tradición noble, noblemente aprendida y más notablemente aún perseguida. Basta para darse una idea ajustada de ello, comparar el vocabulario que Miguel de Unamuno se vio obligado a poner al final de su Vida de Don Quijote y Sancho, con los que figuran en Judios, 
La belleza de estas descripciones reside en gran parte en la elegancia y propiedad de las palabras utilizadas. Este empeño de Cela por rebuscar constantemente en las canteras léxicas del idioma se convierte en un punto nuclear de su estilo. Es raro el estudio sobre su obra que no reflexione sobre este aspecto ${ }^{17}$.

En definitiva, la descripción se recrea en la búsqueda del nombre exacto de las cosas, como vemos en este ejemplo tan ilustrativo:

El aire que rodea al vagabundo todavía huele, con un olor tenue y nutricio, al alfandoque de queso y anís, y a los sequillos de azúcar, y a la charamusca de caramelo rizado, y al tierno bizcochuelo mamón, y al nuégado que se adorna con miel, y al tímido y dulce besico de monja, y al aleluya con el nombre de la novia pintado con merengue y cabello de ángel. El aire que queda más allá del vagabundo también huele, a veces, a suave tierra fresquita, ya al lejano aliento del ganado, y a las doradas, y a las blancas, y a las azules florecillas del monte: el espino y la aliaga, la retama, el romero, el espliego, la mejorana, la jara [...] La señora que ha casado a su nieta se marcha, y el vagabundo, desde su cuneta, se queda mirando cómo se persiguen dos palomas zuranas, dos palomas que, al revés de las nubes que, persiguiéndose, semejaban pájaros, fingen dos nubes veloces al perseguirse ${ }^{18}$.

Esta descripción del ambiente, basada en los olores y en la sorpresa producida ante un vuelo de palomas, tiene al protagonista como centro de esas percepciones: es el vagabundo quien se recrea en la contemplación. Estas paradas «contemplativas» de las acciones no detienen apenas la marcha del relato, pues no se evaden de la temporalidad de la historia ${ }^{19}$. La persona del vagabundo-protagonista actúa como filtro de todas las sensaciones que el narrador (que no es otro que el vagabundo) nos quiere transmitir.

Este modo de focalizar la descripción, según el punto de vista del viajero, nos sitúa ante el movimiento narrativo típico de la «escena», pues la acción, como acabamos de ver, se nos presenta más lenta, más diluida, con predominio de la minuciosidad y la recreación en los pormenores. En consecuencia, la narración asume un ritmo, por seguir la analogía musical genettiana, propio del tempo 'andante', es decir, moderadamente lento y pausado.

Este ritmo narrativo contribuye y tiende a la presentación demorada de los caracteres de los personajes, que van apareciendo a lo largo de los ocho capítulos que componen el libro. Forman un verdadero mosaico de tipos, especialmente interesante y rico y que tendrá una continuidad en la res-

moros y cristianos, uno de ellos de una jerga, el barallete» (Camilo José Cela (acercamiento a un escritor), Madrid, Gredos, 1962, p. 123).

${ }^{17}$ Hay incluso estudios que analizan la obra del autor exclusivamente desde este punto de vista, como por ejemplo el de Sara SuÁrez Solís, El léxico de Camilo José Cela, Madrid, Alfaguara, 1969.

${ }^{18} J M y C$, p. 28

${ }^{19}$ Para la distinción entre la pausa y la escena en este tipo de pasajes, véase Gérard GENETTE, Figuras III, op. cit., pp. 155-160. 
tante producción de Cela. Todos están cortados por un mismo patrón: pertenecen a una escala social baja y, en ocasiones, rayana incluso en lo miserable. Son los vagabundos, las niñeras, los golfillos, el alarife, el limpiabotas, el cabo de la legión, el sacamuelas, el arriero, el pirante, etc. La relación de este rasgo de la prosa de C.J.C. con Baroja ha sido apuntada por la crítica en numerosas ocasiones ${ }^{20}$. Se trata de un desfile torrencial de figuras que se disuelven apenas aparecen. Los perfiles quedan sólo apuntados, pues el objetivo del viaje del vagabundo apremia siempre y va dejando tras de sí un gran número de personajes a los que no se permite intimar con el lector ${ }^{21}$. Afirmación esta última que bien podría aplicarse mutatis mutandis a la prosa de Baroja, como de hecho hizo Ortega y Gasset en la serie de artículos que dedicó al autor vasco ${ }^{22}$.

El recurso a la figura de la etopeya es una constante de este género y de la prosa entera de Cela. Estos retratos de personajes asumen una característica singular aquí, y es'su inextricable vinculación con el paisaje que los rodea. Pozuelo Yvancos habla de «paisaje con figuras» o «criaturas del paisaje» como sintagmas que resumen el principio constructivo del Viaje a

\footnotetext{
${ }^{20}$ Pozuelo Yvancos, en su introducción a la edición del Viaje a la Alcarria (Espasa Calpe, 1991, pp. 9-53), cita las palabras de Ortega en las que considera a Baroja como un escritor de libros de viajes con una preferencia especial por el vagabundaje y la periferia social. Sin duda, la influencia del autor vasco en la narrativa de Cela es muy poderosa.

Esta tendencia de Cela al retrato de los socialmente desamparados guarda una estrecha relación con la pintura «realista» y un tanto descarnada de estos mismos personajes. Ambas facetas están presentes en la obra literaria del pintor Solana, a la que Cela dedicó su discurso de ingreso en la Real Academia en 1957. La enumeración que allí hace de los personajes de Solana podría igualmente referirse a los tipos retratados por el mismo Cela: «Sus chulos, sus criadas, sus mendigos, sus sacamuelas, sus charlatanes, sus boticarios, sus carreteros, sus pellejeros, sus modistillas, sus horteras, sus soldados, sus organilleros, sus criminales, sus cajistas, sus monstruos, sus enfermos, sus encuadernadores, sus verdugos — aquellos verdugos que, ¡vaya por Dios!, iban perdiendo la afición-, sus chalequeras, sus peinadoras, sus tullidos, sus traperos, sus curas, sus zapateros y sus cigarreras, toda la abigarrada fauna ibérica de la que quiso rodearse, formó, en apretadas filas, en compacto y bullidor batallón, tras Solana, que gozaba, como un niño que descubre y que se inventa el mundo, sabiéndose escoltado por tan fiel $-\mathrm{y}$ saltarín y entrañable- guiñol de «cristobitas» de carne y hueso» (La obra literaria del pintor Solana, Discurso de ingreso en la Real Academia Española, Madrid, Papeles de Son Armadans, 1957, pp. 28-29).

${ }^{21}$ Paul Ilie ha destacado con acierto esta faceta de la prosa de C.J.C: «Lo que Cela ve en sus viajes es descrito, pero no analizado; y como lo omitido ha sido visto también, al ser descartado, es por ello mismo juzgado. La inquietud de Cela tiene sus raíces en el idealismo, porque no encuentra nada que se aproxime a su idea de perfección y se ve forzado a seguir adelante. Se convierte en un «Don Juan de los pueblos», que gusta el placer y lo abandona rápidamente, haciendo así más intenso su sabor» (Véase $L a$ novelística de Camilo José Cela, op. cit., p. 115).

22 Ver ORTEGA Y GASSET, «Ideas sobre Pío Baroja», en Obras completas, Madrid, Revista de Occidente, 1966, pp. 69-125.
} 
la Alcarria y que, me parece a mí, pueden aplicarse igualmente a Judíos, moros y cristianos y hacerse extensivos a todos los 'relatos de viajes' de Cela. Es interesante la relación que se establece entre este procedimiento y la teoría del paisaje de Ortega, a la que se pueden vincular dos de sus claves filosóficas más importantes, a saber, el yo y su circunstancia (el hombre y su medio) y su teoría perspectivística:

\begin{abstract}
Ortega explica en esta línea, cómo el paisaje deja de sentirse en cuanto elemento de la naturaleza objetiva para constituir una indagación del alma humana y la vida de todo aquello que no tiene un valor absoluto y abstracto, sino que se resuelve en la relación entre el individuo y el medio; el contorno está vinculado necesariamente a la existencia de cada uno y, por ello, forma parte del mismo. Paisaje y persona, medio y hombre, no serán, pues, realidades enfrentadas, sino intercomunicadas; más aún, interdependientes ${ }^{23}$.
\end{abstract}

Esta unión inextricable de persona y medio resalta con la consideración de Ortega del paisaje como limitación y destino del hombre. El entorno determina la vida de las criaturas que le salen al encuentro al vagabundo y el paisaje, por tanto, cobra vida sólo en la medida en que es contemplado por él. De ahí que los paisajes sean descritos siempre por su mirada atenta y sensible o por la de cualquier inopinado personaje. La Castilla que nos ofrece el autor es unitaria, íntegra, no separa al hombre de sus circunstancias. Recordemos si no el prólogo:

[...] Hablar de su cielo, de su tierra, de sus hombres y sus mujeres, de su cocina, de su bodega, de sus costumbres, de su historia, de sus manías ${ }^{24}$.

Aunque la descripción, como se indicaba más arriba, ocupa un lugar prioritario, el hilo narrativo no desaparece, simplemente se desdibuja en favor de aquélla o, mejor, en favor de la creación de un ambiente, de un entorno. Consecuentemente con la velocidad narrativa pausada, las acciones que pudieran surgir, si es que lo hacen, no abrirán nunca expectativas en el progreso narrativo del relato ${ }^{25}$, pues su existencia efímera no afecta a la trama general, por muy endeble que ésta sea.

Estas posibles y no necesarias acciones, puesto que se integran dentro de un marco descriptivo (de ambiente), nacen con vocación de perentoriedad. En este libro de C.J.C. surgen muchas pequeñas historias vinculadas a los personajes que le salen al encuentro al vagabundo, pero todas ellas

\footnotetext{
${ }^{23}$ José María Pozuelo Yvancos, «Introducción» a la edición del Viaje a la Alcarria, op. cit., p. 22.

${ }^{24} J M y C$, «prólogo», p. 14

${ }^{25}$ Los distintos movimientos narrativos, aplicados a la denominada nueva novela hispánica de los años sesenta y setenta, aparecen convenientemente ejemplificados en el libro de Alfonso SÁNCHEZ-REY, El lenguaje literario de la nueva novela hispánica, Madrid, Mapfre, 1991, pp. 58-70.
} 
son, si se me permite la expresión, microacciones, sin repercusión alguna en el hilo argumental del relato que es el recorrido del protagonista por las tierras de Castilla la Vieja.

\title{
3.3. Las historias intercaladas
}

Precisamente en el uso de estas historias intercaladas, que sobresalen también como un rasgo capital del género, despunta Cela con auténtica maestría. Se acumulan de tal manera en el relato que, sin su presencia, la obra quedaría reducida a mero esqueleto, pura armazón. Estos 'relatos de viajes' se nutren de estas historias, sin las que carecerían de verdadera sustancia narrativa. Aunque en otros géneros suelen ser prescindibles y pueden gozar de vida propia, en este género asumen, por el contrario, una función relevante. Es difícil, por no decir imposible, eliminarlas sin que el relato no se resienta cuantitativa (son muy numerosas) y cualitativamente (su razón de ser es precisamente existir en él). Si se extrajeran de su hábitat natural perderían su peso específico en cuanto a la forma (estructura sencilla y dependiente del relato) y al contenido (muy simple y vinculado a la actividad del protagonista), pues carecen la mayor parte de ellas de la autonomía necesaria para vivir una vida independiente.

Unas veces corresponden a los personajes, que cuentan su historia o la de otros; otras, al protagonista que relata algún suceso, o refiere un episodio histórico que viene al caso, o hace gala de su vasta cultura literaria. Recojo un ejemplo de cada una de las cinco posibilidades aludidas en las que se pueden englobar las historias intercaladas, que adquieren en esta obra, y en el resto de los relatos viajeros de C.J.C., un decisivo papel como elemento vertebrador.

Veamos. Hay personajes que cuentan sus aventuras como éste que se cruza con el vagabundo en el capítulo III:

\begin{abstract}
-Don Fabián continuó su historia. - Entonces un servidor le dijo, dice: «Pues bien, mi señor don Bárulas, exageran quienes tal cosa aseguran, que mi ciencia es corta y no llega a sanar el mal de las almas». Y don Bárulas, que quería que le viese a la muchacha, me atajó: «Pero sana el de los cuerpos, don Fabián, y yo con eso me conformo y no he de pedirle más». Un servidor, que ya había hecho el meritoriaje del humilde, le respondió: «Pues sí, eso sí, don Bárulas, que con la ayuda de Dios aún voy sanando las sangres enfermas, los humores malignos, los mollejones espiritados, los mondongos pestilentes, los bofes acuosos y etcétera, etcétera ${ }^{26}$.
\end{abstract}

O personajes, como el alarife, que gustan de contar sus vidas amenizándolas con fábulas o cuentos adaptados a la situación:

\footnotetext{
${ }^{26} J M y C$, pp. 92-93.
} 
Sobre los troncos, el vagabundo, aun antes de llegar a Santibáñez de Ayllón, se hizo amigo de un viejo guto alarifazgo, que se cuidaba del viento con un capote de parda cuatreada, de buen ver todavía y recia primidera, que le fue contando por el camino las geografías que quedaban a las dos manos y, para dar mayor variedad a la conversación, el cuento de la cigüeña, la zorra y el alcaraván ${ }^{27}$.

Las historias sueltas se ponen también en boca del narrador. El motivo, cualquier lance del camino:

El suceso fue, según el vagabundo pudo colegir, que a la Marcelita la dejaban los novios a pesar de su hermosura porque, a lo mejor, cuando más amartelados estaban y el novio discurría las más discretas lindezas para decírselas al oído, a la niña le brotaba la enfermedad, se le recrudecía y maduraba el flato y lo echaba todo a perder ${ }^{28}$.

Por supuesto, abundan las referencias históricas en boca de nuevo del protagonista o de los personajes, como el diálogo con el viejo mendigo del capítulo II:

— ¡Hermosa villa! —Sí, señor, eso parece. — ¡Ya lo creo! ¡De lo mejor de Castilla y de lo más noble y antiguo! Con los vacceos Roa se llamó Rauda, y Rodacis con los romanos. - ¿Ah, sí? —Sí, señor, y San Astergio, obispo de Osma, convirtió a las vestales de Roa, que tenían fama de hermosas y discretas. -Sí, sí... - Pero el sanguinario de Nerón las mandó degollar a todas. - iCaray! -Sí, señor, a todas sin dejar ni una sola. El viejo mendigo, para decir sus últimas palabras, ahuecó la voz y entornó los ojos con un bien medido gesto de beatífico espanto. -La guerra de los moros la echó al suelo y el conde Nuño Muñoz la repobló en el 939 . El vagabundo está un poco perplejo con las sabidurías del mendigo ${ }^{29}$.

O la evocación histórica, en esta ocasión del narrador, al toparse con una villa de rancio abolengo:

Mombeltrán, a donde el vagabundo llega al tiempo de taparse la luz del día, es solar de noble piedra de historia y villa ilustre y blasonada [...] Mombeltrán es el antiguo Colmenar de las Ferrerías de Ávila, que Enrique IV, el Impotente, ofreció a don Beltrán de la Cueva, fiel vasallo de S.M. que halló la fórmula, no tan mágica, a lo que parece, de convertir a la reina en madre ${ }^{30}$.

Las referencias literarias, por último, se prodigan por todo el libro sin descuidar casi ningún período. El recuerdo, por ejemplo, del Cid al pasar por Castillejo y Valdanzo asoma al instante:

Entre Castillejo y Valdanzo sitúan los sabios el Robredo de Corpes, donde Féliz Muñoz encontró a sus primas, las hijas del Cid ultrajadas por los infan-

\footnotetext{
$27 J M y C$, pp. 39-43

${ }^{28} J M y C$, p. 92.

${ }^{29} J M y C$, pp. 62-63.

${ }^{30} J M y C$, pp. $283-284$.
} 
tes de Carrión. El vagabundo, por entretenerse, puso en romance moderno los versos del cantar $[\ldots]^{31}$.

O la referencia a Cervantes en el mismo capítulo II:

El escudo de Roa lleva una leyenda que dice: Quien bien quiere a Beltrán, bien quiere a su can. El can de Beltrán aparece en el cuartel de la derecha, atado ante un castillo con la puerta cerrada. Chiquiznaque, hablando con Monipodio, en el Rinconete y Cortadillo, usa del mote del escudo de Roa como refrán ${ }^{32}$.

O la interpretación, al contemplar los toros de Guisando, de los versos de Lorca:

Al vagabundo le resulta difícil precisar qué es lo que Lorca quiso decir con lo de «dos siglos». El vagabundo descarta el supuesto, absolutamente improbable y nada poético, de que Lorca aludiera, en esas sus palabras, a nada que pudiera parecerse a señalamiento o precisión de la antigüedad de esos toros. El vagabundo tampoco cree - aunque esto ya no debe rechazarlo tan de plano- que Lorca quisiese indicar que los toros eran dos. Al vagabundo le parece que la expresión «mugieron como dos siglos» la usó el poeta en todos sus poéticos alcances y como imagen de furia y desesperación, de abatimiento, de dolor y de desolación. Lorca, al entender del vagabundo, dijo «dos siglos» poéticamente, como poéticamente pudo haber dicho "mil siglos" ${ }^{33}$.

A esto se añaden, además, la transcripción de coplas, coplillas y versos en general que salpican todo el relato, amenizándolo con esta dimensión folklórica y popular tan propia de la narrativa de Cela.

Como decía antes, ese débil hilo narrativo se enriquece con la presencia de estas historias que, aun no dejando de formar parte de la historia del vagabundo, tienen una existencia meramente pasajera, no trascienden ni pertenecen a la trama general del relato, sino que se extinguen sin abrir ninguna expectativa en el progreso narrativo.

\subsection{Las «pausas descriptivas»}

Ahora bien, si la «escena», con sus diálogos y descripciones (que brillan por su riqueza léxica y la excelencia de sus retratos), es el movimiento narrativo predominante de este género, no obsta para que en ocasiones nos encontremos con las «pausas». Conviene señalar ahora que la descripción no es solo propia de éstas, con las que en ocasiones se la tiende a identificar, sino que es una modalidad narrativa que pertenece a ambos movimientos por igual, como acabamos de ver.

\footnotetext{
${ }^{31} J M y C$, pp. 49-50.

$32 J M y C$, p. 62.

${ }^{33} J M y C$, pp. 304-305.
} 
La diferencia estriba en que las descripciones de las «pausas» suponen realmente un parón en el relato. No están integradas en el hilo narrativo que, en este caso, va trenzando el vagabundo en su travesía. Estas descripciones están desconectadas de la percepción del protagonista, se hacen al margen de su presencia. Podríamos decir que se produce una auténtica suspensión de la historia del viajero, del relato del vagabundo. Aquí sólo hay espacio, el tiempo desaparece momentáneamente hasta que se vuelve a recuperar con la presencia del protagonista, que nos incorpora de nuevo al tiempo de la historia. Veamos un ejemplo:

En la geografía de Castilla la Vieja hay muchos castros y castrillos. Menos en Ávila, la militar, en todas las demás provincias del reino se encuentran estos nombres a cada paso. En Burgos hay cinco castros - Castrobarto, Castroceniza, Castrojeriz, Castromarca, Castrovido-y ocho castrillos: Castrillo de Bezana, Catrillo de la Vega, Castrillo del, Val, Castrillo de Murcia, Castrillo de Riopisuerga, Castrillo de Rucios, Castrillo de Solarana y Castrillo-Matajudíos $[\ldots]^{34}$.

Estas «pausas descriptivas», frecuentes pero no determinantes en el 'relato de viajes', suponen el punto de unión precisamente con el género que conocemos como «guías de viajes». En estas últimas las «pausas descriptivas» adquieren un protagonismo indiscutible. La acción, por mínima que sea, está del todo ausente: sólo interesan la información y los datos históricos y culturales imprescindibles. Las «pausas descriptivas» tienen el dominio absoluto por encima de las 'descripciones escénicas'.

Éste es el caso, curiosamente, del libro de C.J.C. titulado Ávila, publicado por Noguer en 1952. El vagabundo ha desaparecido de la narración y las descripciones responden a la letra al modelo anteriormente expuesto de la técnica de la «pausa»: descripciones que se sostienen sin apoyo en ningún relato $\mathrm{y}$, consiguientemente, desaparición del tiempo, puesto que la ausencia de aquél acarrea la extinción de éste. Esto se acentúa, además, con su presentación paratextual, que trasluce a las claras su intención: la contraportada exhibe un mapa de la ciudad, se incorpora al final un «suplemento de información práctica a la guía de Ávila» y se añaden fotos, con sus correspondientes pies, que ilustran convenientemente el texto.

Ahora bien, en la edición de las obras completas de Cela se incorpora este libro dentro del apartado «Viajes por España», circunstancia que no lo redime de su condición de 'guía', como se desprende del prólogo, fechado en diciembre de 1963:

Entre todas las ciudades españolas, Ávila es, probablemente, aquella que con más claros y diáfanos timbres resuena en mi conciencia; cuando el editor proyectaba su colección de guías españolas y me dio a elegir una ciudad entre

\footnotetext{
${ }^{34} J M y C$, p. 74.
} 
las que más hubieran de acomodarse a mi pluma, no lo dudé demasiado: me quedé con Ávila ${ }^{35}$.

Si aparecen conjuntamente en las obras completas bajo el mismo apartado una 'guía' y unos 'relatos de viajes', es porque aquélla está investida de un cierto rango literario que, aunque desvinculado de toda acción narrativa - rasgo no primordial, insistimos, pero sí indispensable de los 'relatos de viajes' - le viene por la clara voluntad de estilo y cierto distanciamiento de lo documental e histórico que explícitamente manifiesta el autor al final del prólogo antes citado:

Las páginas que siguen no pretenden cosa otra alguna que ser un chisgarabís lazarillo de Ávila; cuando la voz, a veces, se le ahueca, entiéndase que la procesión va por dentro y otros, que no los hueros y solemnes sones, pueden ser sus donaires ${ }^{36}$.

\subsection{La «digresión reflexiva»}

Dedico unas líneas finales, breves, a la ya citada «digresión reflexiva», último movimiento al que se refiere Genette, y que incluye aquellas pausas extradiegéticas (o sea, pertenecientes a una narración marco o en primer grado), vinculadas al ámbito del comentario y la reflexión. No se trata tanto de una interrupción, como es el caso de las pausas, como de un discurso que deja paso a otro tipo de discurso.

Según dije, la prosa viajera de Cela en muchos puntos se aproxima más a la de Baroja y Azorín que a la de otros escritores viajeros del noventayocho, como Unamuno. Esto se hace muy palpable en este movimiento narrativo pues, a diferencia de los 'relatos de viaje' de Unamuno o de Ortega, llenos de consideraciones y comentarios metafísicos, los de Cela fluyen, como hemos visto, por unos cauces muy alejados del ensayo filosófico.

Además de que los propios textos dan testimonio de esta orientación de la prosa de viajes de C.J.C., el mismo autor lo ha corroborado en numerosas ocasiones, como en el prólogo a la segunda edición del Viaje a la Alcarria:

En esto de los libros de viajes, la fantasía, la interpretación de los pueblos y de los hombres, el folklore, etc., no son más que zarandajas para no ir al grano. Lo mejor, según pienso, es ir un poco al toro por los cuernos y decir «aquí hay una casa, o un árbol, o un perro moribundo», sin pararse a ver si la casa es de éste o del otro estilo, si el árbol conviene a la economía del país o no

${ }^{35}$ Camilo José CELA, Ávila, en Obra Completa. Viajes por España 2, Barcelona, Ediciones Destino, p. 65

${ }^{36}$ Ibídem, p. 66. 
y si el perro hubiera podido vivir más años de haber sido vacunado a tiempo contra el moquillo ${ }^{37}$.

O en la nota a la cuarta edición del mismo:

Pues bien: retratando al hombre y a su paisaje, sin meterse en camisas de once varas y en berenjenales que le lleven a sacar conclusiones filosóficas, morales o políticas (que ya sacará el lector, si quiere y acierta), el escritor viajero ya hace bastante ${ }^{38}$.

En suma, la «digresión reflexiva» como movimiento narrativo está ausente de la prosa viajera de C.J.C., más bien como toma de postura y convicción estilística que como simple resultado de una práctica literaria.

\section{Algunas CONSIDERACIONES ACERCA DE LA VOZ NARRATIVA}

Salta a la vista que el narrador de Judios, moros y cristianos, de igual manera que en el resto de los 'relatos de viaje' de C.J.C., cuenta en tercera persona el periplo del protagonista, que se nos presenta bajo la figura de un «vagabundo» ${ }^{39}$. Ya desde el prólogo su identificación con el narrador queda patente: «...el vagabundo ha procurado ordenar su libro con un placentero desorden...» ${ }^{40}$.

Se trata de un simple desdoblamiento del narrador para otorgar mayor verosimilitud al relato. Así pues, protagonista y narrador son la misma persona, como se nos revela por segunda vez en el mismo prólogo:

... lo que el vagabundo imagina que podrá valer de algo al caminante de Castilla la Vieja que le haga la merced de llevar este libro en la maleta... ${ }^{41}$.

El relato, sabemos, va a discurrir por unos márgenes comunes a otros géneros como, por ejemplo, la autobiografía, las memorias, las crónicas, etc., en los que se produce la misma coincidencia, a la que habría que añadir, además, la convergencia de la instancia del narrador con la del autor. Estamos pues ante un desdoblamiento y una identificación, la del narrador con el mismo autor.

Esta identidad se hace patente cuando el narrador se presenta a uno de los numerosos personajes que le salen al encuentro:

\footnotetext{
${ }^{37}$ Ibídem, p. 511.

${ }^{38}$ Viaje a la Alcarria, en Obra Completa. Viajes por España 1, Barcelona, Ediciones Destino, 1965, p. 515.

${ }^{39}$ A la autobiografía en tercera persona dedica Lejeune uno de los apartados del primer capítulo de su libro El pacto autobiográfico y otros estudios, Madrid, Megazul-Endymion, 1994, pp. 89-121.

${ }^{40} J M y C$, prólogo, p. 15

${ }^{41} J M y C$, prólogo, p. 14
} 
- [...] Y ahora déme la mano y dígame su nombre y su naturaleza. El vagabundo dijo su nombre y su pueblo. El mendigo, la mano en la mano, cantó los suyos. -Mi nombre, amigo Camilo, es el de don, porque yo tengo el don, Toribio de Mogrovejo ${ }^{42}$.

Considerado desde este exclusivo punto de vista, la figura de un narrador con semejante perfil coincide con el de la autobiografía pues, al fin y al cabo, nos está contando un tramo de su vida, en esta ocasión el que cubre sus andanzas por Castilla la Vieja, aunque con una intención radicalmente distinta a la de la autobiografía, en la que prevalece sobre todo la experiencia del protagonista y no tanto la información, las noticias o las descripciones que son el objetivo último del 'relato de viajes'.

Estamos ante un narrador autodiegético, por utilizar el término que la narratología atribuye al narrador autobiográfico en el mundo de la ficción. El protagonista del relato nos cuenta su historia, su recorrido, en primera persona (o en tercera, para otorgarle mayor objetividad).

Otro aspecto dentro de este apartado de la voz resulta aquí pertinente. Me refiero al tiempo de la narración, que muestra la distancia temporal que separa al narrador de los hechos que cuenta. Como señaló Genette ${ }^{43}$, la narración puede ser ulterior, anterior, simultánea e intercalada, dependiendo de si la historia narrada ha ocurrido, con respecto al acto de la narración, en el pasado, o tendrá lugar en el futuro, o sucede al mismo tiempo, o bien, por último, se intercala a lo largo del tiempo de la historia.

No cabe duda de que la narración en los 'relatos de viajes' se presenta como una acción simultánea a la historia narrada. Es decir, el narrador está contando unos hechos, no como si hubieran sucedido en el pasado, sino como teniendo lugar en el mismo instante de la narración. Simultaneidad, pues, entre el tiempo de la narración y el tiempo de la historia, que contribuye de manera decisiva a los rasgos de estilo de objetividad, de cotidianeidad e inmediatez que empapan el relato Judíos, moros y cristianos y, por extensión, el resto de la obra viajera de C.J.C.

La utilización de esta técnica narrativa resulta enormemente eficaz, mucho más que la narración ulterior, también posible, según la cual el narrador podría habernos contado su recorrido por tierras castellanas utilizando el tiempo de pasado, tiempo en el que realmente sucedieron las cosas que se nos cuentan. No podemos dejar de considerar que el género de los 'relatos de viajes' se sustenta en experiencias memorizadas, o frecuentemente anotadas, que más tarde o más temprano se transforman, con el oportuno arreglo y aseo estilístico, en el 'relato del viaje' correspondiente, que se muestra en su acontecer inmediato, como narrado en el instante mismo en que aquellos sucesos fueron apuntados o anotados.

\footnotetext{
${ }^{42} J M y C$, p. 70.

${ }^{43}$ Cfr., Figuras III, p. 274.
} 
Por tanto, nos encontramos con un sujeto de enunciación de doble experiencia: la del viaje y la de la escritura. Sujeto, así pues, de doble instancia: sujeto viajero, individual e irreemplazable (en nuestro caso el Cela de carne y hueso que «vagabundea» por los caminos de España), y que, además, (d)escribe esa experiencia. En ocasiones esta situación queda reflejada en el propio texto:

El vagabundo, en apuntar sus sabidurías, tardó todo un día largo, tiempo en el que, por el camino de Villacorta, no pasó ni un automóvil, ni un ómnibus, ni un camión, ni siquiera una bicicleta ${ }^{44}$.

Como narrador y autor convergen en la misma persona, el sujeto con que nos enfrentamos goza de un peculiar estatuto ficcional: es el autor, el escritor, «la voz del hombre de carne y hueso», sin mediación de ningún otro tipo de voz imaginaria. El lector debe asumir una especie de pacto semejante al «pacto autobiográfico», mediante el cual debe suspender su capacidad de incredulidad y aceptar como no ficcional lo que el sujeto nos relata, aunque a veces recurra a la ficción (siempre dentro de los límites de la credibilidad) con tal de garantizar la verosimilitud. Recordemos en este punto que el narrador no siente restricción alguna, ni para dejar de contar todo lo que le ha ocurrido, ni para impedir que su imaginación invente situaciones, personajes, anécdotas con las que, a modo de excipiente, quiera cubrir su recorrido. Lo que interesa al autor es que todo lo que aparezca sirva «siempre al servicio del impreciso y tumultuoso «aire» de Castilla», como citábamos al principio.

\section{CONCLUSIÓN}

Tras el repaso, desde algunas propuestas de la narratología, de las características fundamentales de los 'relatos de viajes' de C.J.C., ilustrado con algunos ejemplos de Judíos, moros y cristianos, podemos afirmar que la llamada literatura viajera de Cela es un auténtico crisol de su producción literaria global.

Sin embargo, esta producción está claramente diferenciada frente a otras series literarias. En efecto, a los tres pilares que sustentan el género - tenue hilo narrativo, descripción predominante sobre la narración y voluntad literaria frente a la histórica y documental- se le añaden otros rasgos narratológicos que lo delimitan de otras series literarias.

A saber, la perfecta sincronía existente entre el tiempo de la historia y el tiempo del relato, que lleva a una narración continua y lineal, en la que están ausentes las anacronías típicas de la narrativa, como las prolepsis y las analepsis.

\footnotetext{
${ }^{44} J M y C$, p. 38.
} 
O el ritmo del relato, que se ajusta sobre todo al mecanismo de las «escenas»y, secundariamente, al de las «pausas» y se muestra absolutamente ajeno a las «digresiones reflexivas». Como consecuencia del ritmo propio de la «escena», el relato discurre con una acción lenta y diluida en la que predomina el interés por el detalle y los pormenores. Así, el diálogo y la descripción se decantan como procedimientos básicos de este movimiento narrativo de la «escena», en la cual la recreación en el léxico y los soberbios retratos de los personajes sobresalen de manera admirable.

La presencia continua también de historias que se intercalan al hilo del viaje del vagabundo subrayan un procedimiento muy propio del género, que Cela explota con enorme eficacia. Perfectamente prescindibles en la mayoría de los relatos - mera incrustación por mor de la 'variatio'-, asumen aquí una función determinante como verdadero y continuo refuerzo de la trama.

Por último, un tiempo de la narración «simultáneo», en que ninguna distancia separa al narrador de los hechos que cuenta, se aviene con la marca de tiempo del presente que asumen estos 'relatos de viajes'.

Estamos, pues, ante un género con unas características perfectamente delimitables, que presenta una producción cuantitativa y cualitativamente variable a lo largo de la historia literaria y que, gracias al ingenio de Cela, consigue no sólo prolongar su existencia tras las huellas de los más célebres escritores de 'relatos de viajes' del 98, como Azorín o Unamuno, sino elevarse a una altura difícilmente igualable.

\section{BIBLIOGRAFÍA CITADA:}

CARrizo Rueda, Sofía, Poética del relato de viajes, Kassel, Reichenberger (Problemata Literaria, 37), 1997.

CElA, Camilo José, Judíos, moros y cristianos. Notas de un vagabundaje por Ávila, Segovia y sus tierras, Barcelona, Destino, 1956.

-, La obra literaria del pintor Solana (Discurso de ingreso en la Real Academia Española el día 26 de mayo de 1957), Madrid, Papeles de Son Armadans, 1957.

GARRIDO DOMínGUEZ, Antonio, El texto narrativo, Madrid, Síntesis, 1993.

GARRIDO GALlaRdo, Miguel Ángel, «Pragmática literaria: las columnas de Francisco Umbral», en La Musa de la retórica. Problemas y métodos de la ciencia de la literatura, Madrid, CSIC, 1994, pp. 214-229.

GENETTE, Gérard, «Fronteras del relato», en AA.VV., Análisis estructural del relato, Buenos Aires, Editorial Tiempo Contemporáneo, 1970.

—, Gérard, Figuras III, Madrid, Lumen, 1989.

-, Gérard, Nuevo discurso del relato, Madrid, Cátedra, 1998.

ILIE, Paul, La novelística de Camilo José Cela, Madrid, Gredos, 1963.

KIRSNER, Robert, The novels and travels of Camilo José Cela, Chapel Hill, North Carolina Press (Studies in the Romance Languages and Literatures, number 43), 1966.

LEJEUNE, Philippe, El pacto autobiográfico y otros estudios, Madrid, Megazul-Endymion, 1994. 
ORTEGa y GaSSET, José, Obras completas, Madrid, Revista de Occidente, 1996.

POZUElo YVANCOS, José María, «Introducción», en Viaje a la Alcarria, Madrid, Espasa Calpe, 1991, pp. 9-53.

SÁNCHEZ-REY, Alfonso, El lenguaje literario de la «nueva novela» hispánica, Madrid, Mapfre, 1991.

SuÁrez Solís, Sara, El léxico de Camilo José Cela, Madrid, Alfaguara, 1969.

ZAMORA VICENTE, Alonso, Camilo José Cela (acercamiento a un escritor), Madrid, Gredos, 1962. 


\title{
RESUMEN
}

A propósito de Judíos, moros y cristianos: el género 'Relato de Viajes' en Camilo José Cela, por Luis Alburquerque García.

Se estudian los rasgos característicos de los 'relatos de viajes' a la luz de la obra $J u$ díos, moros y cristianos, teniendo en cuenta, sobre todo, algunas consideraciones de la narratología sobre el tiempo y la voz. Así, la perfecta sincronía entre el tiempo de la historia y el del relato, la narración simultánea y el ritmo propio de la «escena», actuarían como huellas inequívocas del género, en el que predominan las «descripciones escénicas», los diálogos, las historias intercaladas y el exquisito cuidado por el léxico.

Se pondera en este artículo por qué los 'relatos de viajes' de Camilo José Cela suponen una aportación sustantiva en el conjunto de su obra, lo que se ilustra con ejemplos extraídos de la obra de referencia, libro importante dentro del género y poco atendido por la crítica, debido quizá a la sombra proyectada por el Viaje a la Alcarria. Cela descuella en la utilización de los susodichos recursos por encima incluso de predecesores noventayochistas tan insignes en el cultivo de este género como Unamuno o Azorín.

Palabras clave: literatura de viajes, relatos de viajes, narratología, Judíos, moros y cristianos, Camilo José Cela.

\begin{abstract}
The characteristic features of the "travel narratives" are being studied in light of the work Judios, moros y cristianos, keeping in mind, above all, some considerations concerning narratology about time and voice. Thus, the perfect synchrony between the time of the story and that of the narrative, simultaneous narrative and the natural rhythm of the "scene", would act like unmistakable traces of the genre in which predominate "descriptive scenes", dialogues, inserted stories and exquisite care for the sake of the lexicon.

It wonders in this article why Camilo José Cela's "travel narratives" imply a sustantive contribution in the entirety of his work, which it is illustrated with examples extracted from the reference work, an important book within the genre and paid little attention to by the critics, perhaps owing to the shadow projected by Viaje a la Alcarria. Cela stands out in the use of the above-mentioned resources on top of even predecessors of the Generation of 1898 , so illustrious in the cultivation of this genre, like Unamuno or Azorín.
\end{abstract}

Key words: travel literature, travel narratives, narratology, Judíos, moros y cristianos, Camilo José Cela. 